\title{
COMENTARIO A LA CRÓNICA DEL MILICIANO ORWELL
}

COMMENTARY ON ORWELL'S MILITIAMAN CHRONICLE.

\author{
Víctor Manuel Urbán Palacios \\ Universitat de València (España)
}

Recibido: 20-05-2012

Aceptado: 26-06-2012

\begin{abstract}
Resumen: En estas páginas trataré de acercarme a la trágica experiencia del combate, siguiendo principalmente el texto Cataluña 1937, en el que Orwell narra su paso por la milicia armada del POUM en el frente de Aragón, su participación en los Hechos de Mayo, la represión y encarcelamiento de los dirigentes trotskistas y su penosa salida del territorio republicano.

Palabras-clave: Orwell, soldado, guerra, POUM, República, miliciano, frente, trinchera, enemigo, Rebelión en la Granja, 1984.
\end{abstract}

\begin{abstract}
In these pages I will try to approach the tragic experience of combat, mainly following the text Homage to Catalonia, in which Orwell narrates his way through the armed militia of the POUM in the Aragon Front, his participation in the Barcelona May Days, the repression and imprisonment of the Trotskyist leaders and his painful departure of Republican territory.

Key-words: Orwell, soldier, war, POUM, Republic, militiaman, front, trench, enemy, Animal Farm, 1984.
\end{abstract}

\section{De qué lleva a alguien mentalmente sano a coger un fusil y lanzarse al monte a matar o ser matado por sus semejantes.}

El propio planteamiento de la pregunta deja claro que el hecho de que miles de voluntarios ${ }^{1}$ acudan casi en masa a alistarse en un ejército, sabiendo

[1] Planteamos la cuestión presuponiendo cierta libertad humana. Si el enrolamiento deja de ser voluntario, la respuesta es obvia: quien desatiende el requerimiento formal de defender a la Madre Patria es fulminantemente hecho reo por deserción, lo que en algunos supuestos incluso se paga con la muerte. Pena que, por otro lado, no debería caer, en principio, ni siquiera sobre el enemigo 
que el destino que aguarda es la primera línea de fuego, exige una explicación, quizá más detallada de la que podremos dar yo ahora. Si se nos permite la broma, en El sentido de la vida, de los Monty Python, en su capítulo sobre la guerra, cuando el oficial invita a sus soldados en formación a romper ésta e ir al cine si lo prefieren, sencillamente, se queda desfilando sólo por el patio de armas. En principio cualquier actividad, ver una película o pasear por el zoo, apetece más que tratar de resolver a cañonazos las diferencias entre unos señores a los que la potencial víctima/victimario no conoce de nada.

Pero parecerá que se esquive una primera respuesta evidente a la pregunta con un movimiento de trilero: no podemos comparar ir al cine con ir a la guerra, ya que lo primero es ocio y lo segundo, digámoslo así, negocio. Es decir, dado que se trata de una actividad retribuida, es razonable suponer que al menos parte de los que deciden enrolarse con destino al frente lo hacen por dinero. Si bien es cierto que el sueldo de un recluta no da para muchas alegrías, también lo es que en la guerra la manutención y demás necesidades básicas corren por cuenta del Estado. Sabemos por Orwell que algunas familias enviaban a sus hijos ridículamente pequeños a la guerra por conseguir tanto una paga extra como algo de pan que llevarse a la boca.

Pero más allá de los motivos pecuniarios encontramos los morales y psicológicos. Orwell nos cuenta que «Había viajado a España con el proyecto de escribir artículos periodísticos, pero ingresé en la milicia casi de inmediato, porque en esa época y en esa atmósfera tal actitud parecía ser la única posible.»" Esa "atmósfera" es la de calles llenas de carteles, hablándote directamente a ti, tratando de hacerte sentir culpable y dando la posibilidad de redención a partes iguales; altavoces por Las Ramblas lanzando consignas antifascistas (en este caso) o canciones militares y desfiles de soldados apunto de marchar al frente. Nuestro cronista entiende su deber para con la República democrática de trabajadores como una cuestión de dignidad y decencia. Sin duda psicólogos y sociólogos explicarían el mismo fenómeno en términos, al menos, de sugestión.

Dejemos un momento a nuestro autor principal y acordemos, con Joan Fuster, que el hombre medio, sea quien sea si es que es, simplemente se aburre de su rutinaria vida. La guerra es, pues, una vía de escape para la adrenalina y sus efectos, frente a los cuales el deporte o el cine de acción apenas pueden ser malos canalizadores. Se trataría, a pesar de la disciplina militar, seguramente más propia del cuartel que del frente, de un periodo anárquico en que los soldados, por lo general jóvenes, pueden dar rienda suelta a sus pasiones sin demasiados límites. En el punto tres veremos que esta teoría no concuerda

capturado.

[2] J. Orwell, Cataluña 1937, pág. 10.

THÉMATA. Revista de Filosofía, Nº48 julio-diciembre (2013) pp.: 165-172 doi: 10.12795/themata.2013.i48.14 
con la realidad que se encuentra Orwell en las trincheras, o al menos con su percepción de ésta.

\section{De la instrucción previa a lanzarse al monte a matar o ser matado.}

Cualquier ejército necesita, evidentemente, antes de mandar a sus hombres al frente, darles una formación militar más o menos básica, especialmente si sus filas se nutren principalmente de voluntarios, en muchos casos adolescentes sin ningún tipo de experiencia marcial. Aunque no es menos cierto que en no pocas ocasiones tal formación se imparte de una manera apresurada (la urgencia militar no siempre es compatible con la estrategia y el sentido común). La República no tenía demasiado tiempo para formar a sus milicianos voluntarios, según Orwell, porqué le era imperativo al gobierno mandarlos con la mayor urgencia al frente para frenar las tropas sublevadas mientras se instruía (y casi es un decir) más adecuadamente al Ejército Popular.

No nos extenderemos apenas en este apartado, porqué apenas sí se extendió la formación militar de nuestro autor: Tras unos días formando en los Cuarteles Lenin se consideró que los reclutas estaban listos para desfilar públicamente y en pocas semanas se les mandó al frente. Nótese que hablamos exclusivamente de formaciones y desfiles. Y es que eso, y sólo eso, era lo que se enseñaba a los voluntarios antes de mandarlos a matar o morir. La razón es de una lógica aplastante: en todo el cuartel no había más armas que las pocas usadas ineludiblemente por los centinelas. Podemos verlo también en una escena de la película Tierra y libertad en que una miliciana pierde los nervios ante la evidencia de que su instrucción en Barcelona no va a pasar de desfilar con un palo al hombro, casi como si de un desesperado juego de niños se tratara. Finalmente, Orwell y sus compañeros reciben una única clase teórica de cinco minutos, ya en el frente de Aragón, sobre el montaje y desmontaje de un fusil. Con semejante preparación, cuesta creer que el Ejército "Nacional", compuesto principalmente por oficiales de carrera y chavales que se encontraban casualmente haciendo el servicio militar en los cuarteles sublevados, no barriera las milicias voluntarias fulminantemente ${ }^{3}$.

\section{Del frente y la trinchera.}

Una vez en las trincheras, no hay lugar para una visión mitificada de la guerra como lugar natural de la gloria y el heroísmo: «Secretamente, sentía miedo [...]tenía edad suficiente para recordar la Gran Guerra[...]Para mí, la guerra significaba estruendo de proyectiles y fragmentos de acero que debían esquivarse; por sobre todo, significaba lodo, piojos, hambre y frío. Es curioso,

[3] Dejaremos los debates sobre la inicial superioridad aérea republicana para los expertos militares.

THÉMATA. Revista de Filosofía, № 48 julio-diciembre (2013) pp.: 165-172 doi: 10.12795/themata.2013.i48.14 
pero temía al frío mucho más que al enemigo» ${ }^{4}$ o «Gloria de la guerra, sin duda! En la guerra, todos los soldados tienen piojos [...] Los hombres que lucharon en Verdún, Waterloo, Flandes, Senlac, Las Termópilas, todos ellos tenían piojos arrastrándose por sus testículos. $\aleph^{5}$ Difícilmente encontraremos una visión menos gloriosa de esta increíble actividad humana.

A pesar de las reflexiones en nuestro primer punto sobre la búsqueda de aventura como uno de los principales motores de furor guerrero, Orwell casi se lamenta repetidamente de no encontrar nada parecido en la primera línea de fuego. Es más, se aburre; su principal misión no es menos rutinaria que la de un oficinista: patrullar, hacer guardia, recoger leña, rebuscar patatas en los bancales próximos... Y de vez en cuando, sí, disparar algunos tiros, muy pocos, a una trinchera enemiga demasiado lejana para esperar matar a un fascista (su rocambolesca meta personal) si no es por casualidad.

Aún con esta rutina, la falta de sueño y la incomodidad, junto con las condiciones atmosféricas y las balas perdidas, son el principal dolor de cabeza de Orwell. Apenas dormía cuatro horas cada día, en unos agujeros en las trincheras que llamaban chabolas, cubierto con una mala manta. Siempre con el "uniforme" zarrapastroso y las botas embarradas, y el fusil nunca muy lejos (o clavándose un revolver en las costillas) por si les sorprendía un sorprendente ataque enemigo. Más que gloria y heroicidad, lo que se encuentra un soldado en el frente es incomodidad, raciones oscilantemente pasables y un perpetuo estado de somnolencia. Y cuando por fin le disparan comprueba con humillación que se siente asustado. Finalmente, aunque termina con los nervios desechos, sentirá que no ha hecho su parte en la batalla, sólo recibir raciones.

Respecto a las personas que puede uno encontrarse en la guerra, nuestro cronista nos dice que ésta atrae a chusma de diversas partes del mundo, aunque afirma, y quizá este punto sea especialmente susceptible de ser tergiversado por la subjetividad, que en su bando había relativamente pocos. Tampoco podemos asegurar que no sea la misma guerra la que trastoque los planteamientos morales de los que la sufren hasta convertirlos en "chusma". Sea como fuere, se nos muestra un escenario en que no es extraño que se "roben" entre los mismos compañeros los fusiles, y en que los camaradas de un herido han de visitarlo raudos al hospital, no por cortesía sino para evitar que los practicantes les urten el revólver o el reloj.

Y por lo que respecta al armamento de combate, la realidad pronto hará a Orwell abandonar su pretensión casi infantil de disparar una ametralladora: «La carencia de materiales de guerra de todos los tipos era total [...]En verdad, se trataba de armas casi inútiles. Estaban hechas con partes de otras armas, ningún cerrojo correspondía a su fusil, y podía darse por descontado que el

[4] J. Orwell, Cataluña 1937, pág. 26.

[5] J. Orwell, Cataluña 1937, pág. 88.

THÉMATA. Revista de Filosofía, Nº48 julio-diciembre (2013) pp.: 165-172 doi: 10.12795/themata.2013.i48.14 
setenta y cinco por ciento dejaba de funcionar después de cinco tiros.» ${ }^{6}$ Esta queja, por lo general más bien sorda, de los soldados respecto de su armamento parece repetirse en innumerables guerras, especialmente en las modernas, y contribuye a darles cierta sensación de abandono por parte de su gobierno y alto mando allá en la retaguardia.

Sea como fuere, entre los mucho o pocos tiros del frente, todos los soldados piensan en una única cosa, en el fin de la guerra. Porque si algo bueno tienen una guerra es que al fin y al cabo, esperemos, tendrá que acabarse algún día, aunque dure cien años. Cuando los militares vuelven a casa, a poder ser vivos, esperan hacerlo como héroes en medio de un desfile vistoso entre chicas guapas y agradecidas ondeando sus banderas. Y rodeados por sus familiares, ignorantes, eso sí, de muchas de las cosas que los soldados han visto en el frente, que jamás les contarán, y que les habrán cambiado para siempre. Pero este caluroso recibimiento, especialmente la primera parte, no siempre se recibe.

El fin ideal de la guerra, incluso en el sentido de finalidad, es la victoria. (Aunque Orwell afirma que el propio hecho de plantar cara a la opresión y perder ya es mejor que dejarse avasallar mansamente). Peroen el frente, y con una visión pragmática de la realidad que le rodea, para cada soldado particular la victoria puede ser que no le mate el enemigo, del que hablaremos en nuestro siguiente apartado. Y mientras el verdadero punto final de la guerra llega, el guerrero se conformara con el punto seguido de las licencias de que hablaremos en nuestro punto quinto.

\section{El enemigo: ese prójimo que me matará si no le mato.}

Desde la generalización del uso militar de la pólvora, el enemigo ya no es lo que era. Es decir, descontados los comandos de élite y algún enfrentamiento cuerpo a cuerpo poco usual entre tropas de trinchera, un soldado puede mancharse con su sangre propia o con la de sus compañeros, pero difícilmente con la del enemigo. Es más, podría decirse que el francotirador es el único soldado que ve la cara de su objetivo antes de destrozársela de un certero balazo. El resto de militares se limita a disparar aproximadamente contra la posición de unos bultos tan lejanos que parecen hormiguitas y a esperar que haya "suerte". Podríamos pensar que tan absurdo procedimiento ya ha sido superado y que en las guerras posmodernas, con cámaras instaladas en unos misiles tan precisos que resulta sospechoso cuando fallan, esto ya no es así. Pero sabemos por los videos, amateurs o profesionales que nos llegan de la actual guerra de Afganistán, que hoy por hoy los soldados occidentales siguen "tirando a bulto" contra laderas montañosas en que sospechan, con más o menos atino, que se refugian los talibanes que también disparan contra ellos. Verbigracia, el con-

[6] J. Orwell, Cataluña 1937, pp. 42 y 43.

THÉMATA. Revista de Filosofía, Nº48 julio-diciembre (2013) pp.: 165-172 doi: 10.12795/themata.2013.i48.14 
tingente español actualmente desplegado en aquél país no cuenta con gafas de visión nocturna más que para los oficiales, que indican a sus hombres, como buenamente pueden, donde se localiza el enemigo a abatir.

Empero esta deshumanización del enemigo, que por otro lado ya se daba en el '37 (Orwell narra como soldados jovencísimos sonríen cuando los suyos disparan contra los "puntitos" de las trincheras enfrentadas) y seguramente también en las guerras de griegos y romanos contra bárbaros o salvajes, no puede ser completa. Más allá de la propaganda, el enemigo es una persona que incluso domina el arte de la guerra, y el soldado que trata de no ser abatido por él bien lo sabe. Un ejército necesita tener en frente no sólo a una persona, sino a un guerrero. La "virilidad" del enemigo es el patrón por el cual medirá la suya propia.

\section{Licencias y retaguardias. Un interregno de falsa normalidad.}

A pesar de que, como hemos dicho, en ciertos aspectos la guerra deshumaniza a quienes tienen la desgracia de padecerla (en otros quizá los humaniza), los soldados son personas y no máquinas y es incluso una necesidad estratégica darles licencia de vez en cuando para que descansen de los horrores del frente. Aunque la misma necesidad militar exige que estas "vacaciones" no excedan de una o dos semanas por cada dos o tres meses de combate. Posiblemente la mayoría de los ejércitos de la historia hayan otorgado a sus combatientes algún tipo de permiso más o menos prolongado. Y seguramente todos los soldados hayan hecho poco más o menos lo mismo durante su descanso. Teniendo en cuenta que se trata de hombres jóvenes, en ocasiones extremadamente jóvenes, que normalmente llevan meses sin ver a una mujer (en la trincheras republicanas esto no era exactamente así) y que cobran varios meses de escasa paga de golpe y con pocos días por delante para dilapidarla, podemos hacernos una idea de en qué consiste parte del descanso del guerrero. Aunque los excesos de Orwell son bien distintos: nuestro autor nos cuenta como pasaba los días durmiendo y despertándose tan solo para comer hasta sentirse mal. Lo que más deseaba en el frente era sencillamente una cama con sábanas.

El motivo de la licencia es conseguir que los soldados olviden la guerra, aunque esto parece un tanto extraño si no abandonan el país que la sufre. Pero Orwell nos enseña que en la retaguardia la guerra quizá no siempre está tan presente, aunque sea en espíritu, como la decencia mandaría. Dicho en otras palabras: sabemos por nuestro autor que en Tarragona, y es sólo un ejemplo, parte de la sociedad (da igual que sean burgueses o no) se dedicaba a bañarse despreocupadamente en el Mediterráneo mientras los hijos de ésta, ergo hermanos, se mataban unos a otros a pocos cientos de quilómetros. En el colmo de la inmoralidad, los turistas seguían exigiendo que se les sirviesen platos exquisitos con todo el ceremonial, mientras que la población civil (al menos la pobre) padecía la escasez y la inflación. Y esto no es exclusivo de la Guerra de España. Algu- 
nos de los habitantes de los hoteles son los periodistas que escriben las crónicas, falseadas hasta decir basta, de lo que sucede en otras provincias, más castigadas por la guerra y que ellos nunca visitarán.

De todas maneras, en las guerras del s. XX la diferencia entre vanguardia y retaguardia, desgraciadamente, se reduce en tanto que cualquier ciudad es susceptible de verse obligada a recordar la triste realidad de la guerra pudiendo ser bombardeada, principalmente debido a los avance en aviación militar, en cualquier momento. Orwell nos narra, de pasada, algunos ataques aéreos sobre Barcelona; aunque Guernica es sin duda la prueba más palpable.

\section{Algunas conclusiones y de como su paso por trincheras y ba- rricadas marcó a Orwell y su obra posterior.}

La guerra es una catástrofe que no deja indiferente a nadie que la viva en toda su intensidad, y el caso de Orwell no iba a ser diferente: «Ese período que entonces me pareció tan inútil y vacío de acontecimientos, tiene ahora gran importancia para mí. Es tan distinto del resto de mi vida [...] Fue espantoso mientras duró, pero ahora constituye una región en la que a mi mente le resulta provechoso internarse.» ${ }^{7}$

No obstante, podemos afirmar que la verdadera piedra de toque del idealismo (entendido en un sentido, por así decirlo, romántico) de nuestro cronista fueron la terribles purgas políticas de corte y motivación estalinista y las batallas internas entre las fuerzas "republicanas" catalanas que sirvieron de excusa, si es que tal circunloquio era necesario para prender tales teas inquisitoriales. Orwell llega a España en el '36 como corresponsal de guerra y prácticamente de inmediato se enrola en la milicia del POUM, ansioso de defender a la clase obrera española. Por más que considerara a ésta hermana, no hemos de olvidar que bien podría haber tomado otra actitud mucho más distanciada ante una guerra que en principio no tenía por qué ser la suya. Sin ánimo de entrar a debatir el mesianismo propio del marxismo y otras ideologías, su esperanza (al menos) en que la organización político-social humana era mejorable en la práctica es evidente. Seis meses después, nuestro héroe huye, sin estar completamente recuperado de sus heridas de guerra, de sus antiguos "compañeros", saliendo de España de manera alegal tras pasar varias noches vagabundeando por Barcelona. Para eso debió esconderse de los policías de una república la defensa de la cual casi le cuesta la vida, en medio de una espantosa caza de brujas en que desaparecieron en cárceles más o menos secretas compañeros y amigos personales suyos, alguno de los cuales parece que fue fusilado.

Para soportar aquello no prepara ninguna instrucción militar. Es decir, cuando alguien va a la guerra espera, aun con todo el lustre de gloria y honor,

[7] J. Orwell, Cataluña 1937, pág. 120.

THÉMATA. Revista de Filosofía, $\mathrm{N}^{\circ} 48$ julio-diciembre (2013) pp.: 165-172 doi: 10.12795/themata.2013.i48.14 
encontrar muerte y destrucción. Pero al menos cree que estará maniqueamente claro quién es el enemigo con el que intentar (co-)matarse y quien el aliado-compañero que le ayudará. Y aún así, la experiencia ya es bastante traumática. (La casuística psicológica y psiquiátrica da buena cuenta de ello). Pero vivir una guerra civil, incrustada a su vez dentro de otra contienda entre hermanos, dio al traste con el esquema mental de Orwell y con todo el optimismo antropológico que éste pudiera contener. La tremenda impresión que causaron sus seis meses en nuestro país marcaron el pensamiento y literatura orwelliano más allá de $C a$ taluña 1937. En este sentido, podemos trazar una solución de continuidad que va desde el texto aludido hasta 1984, pasando por Rebelión en la granja.

En el enfrentamiento narrado en Animal Farm entre Napoleón y Snowball, vemos como Orwell reproduce el mismo esquema de persecución de trotskistas por parte del estalinismo y como Snowball (Trotski, el POUM) se ve obligado a huir, o al menos de eso es acusado, tras las líneas enemigas. (De Nin, líder del POUM, también se decía que se había refugiado en territorio franquista.) Y eso permite a Napoleón afirmar que su rival está detrás de toda desgracia que suceda en la granja, pues habría urdido un diabólico plan, encamado con el enemigo, para acabar con todo lo logrado en la pasada revolución.

La represión y encarcelamiento de disidentes después de mayo del '37, y sobre todo el clima irrespirable que esto conllevó, es el telón de fondo, a la par que el mensaje principal, de 1984: Carteles de propaganda por doquier, megáfonos (o telepantallas) bombardeando consignas político-militares día y noche buscando una brutal manipulación psicológica de la población, miedo a que cualquiera pueda ser un espía, temor a parecer un conocido de los cada vez menos disidentes, encarcelamientos secretos y arbitrarios...

En general, podemos decir que si en Cataluña 1937 hay esperanza (cada vez menos, conforme se precipitan los acontecimientos) en la humanidad y en un futuro mejor; en Rebelión en la Granja Orwell ya tiene asumido que cualquier revolución no hará sino cambiar un tirano por otro. Pero 1984 ya es el infierno dantesco en que se debe abandonar toda esperanza de libertad y retorno. Ni siquiera hay una fase inicial con alguna posibilidad de liberación, sumerge al lector de lleno en una anti-utopía en que su protagonista duda que jamás vuelva a pisar la Tierra un ser humano libre.

\section{Bibliografía:}

- George Orwell, Cataluña 1937, Ed. Proyección, Buenos Aires, 1964.

- George Orwell, Rebelión en la granja, Ed. Destino, Barcelona, 2007.

- George Orwell, 1984, Ed. Destino, Barcelona, 2005.

· Joan Fuster, Diccionari per a ociosos en Obres Completes VI, Ed. 62, Barcelona, 1992. 